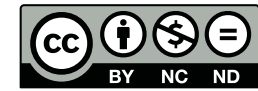

Estudos Teológicos foi licenciado com uma Licença Creative Commons Atribuição - NãoComercial - SemDerivados 3.0 Não Adaptada

http://dx.doi.org/10.22351/et.v57i1.2953

\title{
Martin Bucer e os Judeus ${ }^{1}$
}

\author{
Martin Bucer and the Jews
}

\section{Görge K. Hasselhoff ${ }^{2}$}

Resumo: Tradicionalmente, a atitude em relação ao judaísmo de Martin Bucer, o reformador protestante de Estrasburgo, é julgada a partir de "Judenratschlag" (Conselho sobre os judeus) (1538), que ele escreveu junto com alguns pastores de Hesse a pedido do landgrave Felipe II. Este artigo faz uma aproximação diferente examinando as obras de Bucer de acordo com sua ordem cronológica. Sua atitude em relação à língua hebraica não era diferente daquela dos humanistas contemporâneos e, repetidamente, em seu comentário anonimamente publicado sobre os Salmos, utilizou a literatura exegética judaica pertinente. Com judeus contemporâneos como Josel de Rosheim ele mantinha uma relação pessoal amigável. Nesse contexto, é ainda mais surpreendente que ele seja o coautor do áspero livro "Judenratschlag". A razão para isso poderia ser que Bucer era um teólogo tradicional que cresceu na tradição dominicana. Portanto seu conselho deveria ser visto como um conselho político com traços teológicos. No entanto, Bucer não era tão antijudaico e cheio de ódio judeu como seu companheiro reformador Martim Lutero.

Palavras-chave: Rosel von Josheim. Estrasburgo. Filipe de Hesse. Judenratschlag.

Abstract: Traditionally, the attitude towards Judaism of Martin Bucer, the protestant reformer of Strasbourg, is judged on the "Judenratschlag" (1538) that he wrote together with some Hessian ministers on request of Landgrave Philipp II. This article takes a different approach by scrutinising Bucer's works according to their chronological order. His attitude towards the Hebrew language was not different from that of contemporary humanists, and time and again in his anonymously published commentary on Psalms he made use of pertinent Jewish exegetical literature. With contemporary Jews like Josel of Rosheim he was personally on a friendly level. Against this background it is all the more astonishing that he co-authored that rather harsh "Judenratschlag". The reason for

1 O artigo foi recebido em 27 de fevereiro de 2017 e aprovado em 04 de abril de 2017 com base nas avaliações dos pareceristas ad hoc.

Tradução: Martin Volkmann; revisão: Rudolf von Sinner, com apoio técnico da bolsista de Iniciação Científica Fabiane Schmidt. - Uma versão alemã deste artigo mais detalhada, principalmente no tocante às notas, foi publicada em: Judaica, v. 68, p. 343-373, 2012.

2 Doutor em Teologia pela Universidade de Heidelberg, Alemanha. Atualmente, é livre-docente em História da Igreja e da Teologia na Universidade Politécnica de Dortmund. Em 2012, foi professor visitante na Faculdades EST, em São Leopoldo/RS. Contato: goerge.hasselhoff@udo.edu 
that might be that Bucer was a traditional theologian who grew up in the Dominican tradition. Therefore his advice should be seen as a theologically coloured political advice. Nonetheless, Bucer was not as anti-Jewish and filled with Jew hatred as his fellow reformer Martin Luther.

Keywords: Rosel von Josheim. Straßburg. Philipp von Hessen. Judenratschlag.

história da primeira geração da Reforma poderia ser descrita como sendo

Aa história da importância das ordens religiosas. Martim Lutero era monge da ordem agostiniana - isso é do conhecimento geral. Mas também outros reformadores tiveram sua formação em mosteiros, conventos e escolas monásticas ou, no mínimo, foram marcadamente influenciados por teólogos de ordens religiosas. Assim, por exemplo, o professor de hebraico e colaborador de Ulrico Zwínglio, Conrad Pellikan, durante muitos anos foi membro da ordem dos franciscanos, e Martin Bucer, de quem trataremos a seguir, foi membro da ordem dos dominicanos. ${ }^{3}$ Ao que tudo indica, tiveram forte influência na fase inicial de sua teologia especialmente Tomás de Aquino, respectivamente o tomismo marcado por Cajetano. Mesmo assim, Bucer sempre permanece um tanto como o "grande desconhecido" da época da Reforma. A isso correspondem formas surpreendentes como ele seguidamente é caracterizado como, por exemplo, a seguinte: Martin Bucer é um "teólogo provocador" ["scharfmacherischer Theologe"]. Esse é o juízo de um historiador sobre a postura do reformador de Estrasburgo em relação aos judeus. ${ }^{4}$ Como, no entanto, na historiografia da Reforma, Bucer em geral é descrito como teólogo irênico ${ }^{5}$, tal juízo é muito surpreendente. Além disso, impõe-se a pergunta se a relação de Bucer com os judeus e sua recomendação em relação aos judeus de 1538 são parte central de sua teologia reformatória ou, no mínimo, consequência dela. Assim, faremos, em duas partes distintas, uma análise da temática "Bucer e o judaísmo": num primeiro momento, sob o enfoque biográfico e, num segundo momento, a partir da leitura de textos selecionados de Bucer.

3 Desde os anos 50 do século XX, as obras de Martin Bucer são editadas criteriosamente. Os volumes da edição crítica são abreviados como segue:

BDS $=$ Martin Bucers Deutsche Schriften $=$ Martini Buceri Opera Omnia, ser. I

$\mathrm{BOL}=$ Opera Latina $=$ Martini Buceri Opera Omnia, ser. II

$\mathrm{BCor}=$ Correspondance de Martin Bucer [ab v. 4: Martin Bucer Briefwechsel - Correspondance] $=$ Martini Buceri Opera Omnia, ser. III

4 HILLERBRAND, Hans J. Vom geistigen "Holocaust" zur rechtlichen Toleranz: Bemerkungen zum Thema Johannes Reuchlin und die Reformation. In: HERZIG, Arno (Org). Reuchlin und die Juden. Sigmaringen: Thorbecke, 1993. p. 109-122. O contexto da p. 118 diz o seguinte: "No despacho da resolução do Hesse em relação aos judeus (1539), o conde de tendência tolerante [isto é, Felipe de Hesse [...]] tinha que ocupar-se com o teólogo instigante Martin Bucer".

5 Cf. ERICHSON, Alfred. Martin Butzer der elsässische Reformator. Strassburg, 1891. p. 55 com citação de Ambrosius Blaurer. 


\section{Aspectos biográficos}

Martin Bucer nasceu em 11 de novembro de 1491, oito anos após Martim Lutero, em Schlettstadt (atualmente Seléstat). Com 15 anos foi entregue à guarda da ordem dominicana em Schlettstadt. ${ }^{6} \mathrm{O}$ mais tardar na segunda metade da segunda década do século XVI, Bucer estudava e lecionava nos conventos de sua ordem em Heidelberg e Mainz. Mesmo que Bucer tenha se afastado gradativamente da ordem dominicana na sequência da disputa de Lutero em Heidelberg de 1518, sua formação dentro da ordem teve, sob muitos aspectos, influência marcante em seu modo de pensar. Por um lado, provém dessa época seu amplo conhecimento da teologia de Tomás de Aquino; por outro lado, a relação de seus livros de 30 de abril de 1518 evidencia um amplo interesse tanto na literatura da ordem quanto em obras humanistas. ${ }^{7}$ Entre os livros de Bucer constam, entre muitos outros, várias obras de Tomás de Aquino (p. ex. Summa theologiae, Summa contra gentiles, Scriptum super Libros Sententiarum, Questiones de veritate, Comentário sobre a Metafísica), Comentário sobre sentenças de Petrus de Palude (1280-1342), comentários de Tomás de Vio Cajetano (em relação à Suma Teológica de Tomás Aquino, bem como ao Pentateuco), mas também obras de autores clássicos da filosofia, tais como Aristóteles e Cícero, bem como de Paulus Ricius, Marsilio Ficino, Laurentius Valla, Jacques Lefèvre d'Étaples e Erasmo. Interessante em relação ao assunto deste estudo é o fato de que Bucer possuía uma edição hebraica dos Salmos de Conrad Pellikan e uma edição da Defensio Johannis Reuchlini contra calumniatores suos Colonienses (Tübingen, 1514; "Defesa de João Reuchlin contra os caluniadores de Colônia") ${ }^{8}$. Nessa questão em torno de Reuchlin, Bucer, ao que tudo indica, se posicionava a favor de Reuchlin, não obstante transpareça, em comentários posteriores, uma proximidade maior com a polêmica antijudaica de Pfefferkorn. ${ }^{9}$ Além disso, encontra-se entre os livros de Bucer uma gramática hebraica. Provavelmente trata-se de הדיקדוק חלק de David Kimchi. ${ }^{10}$ Portanto podemos concluir que Bucer esteve profundamente enraizado tanto no humanismo quanto no "puro e rígido tomismo" $" 11$ nos inícios do século XVI.

6 Com relação a detalhes biográficos, cf. em especial GRESCHAT, Martin. Martin Bucer: Ein Reformator und seine Zeit. München: Beck, 1990.

7 A relação de livros consta, com comentários, em BCor 1: (Jusqu'en 1524), publicado por ROTT, Jean. Leiden: Brill, 1979. (Studies in Medieval and Reformation Thought, v. 25). p. 42-58.

8 Cf. BCor 1, 53, n. 32.

9 Com relação à disputa de Pfefferkorn. cf. KIRN, Hans-Martin. Das Bild vom Juden im Deutschland des frühen 16. Jahrhunderts dargestellt an den Schriften Johannes Pfefferkorns. Tübingen: Mohr Siebeck, 1989. p. 121-185.

10 A referida gramática de David Kimchi (1105-1170) só é comprovada na forma impressa a partir de 1529. Porém, eu não excluo a possibilidade de que Bucer tenha possuído um manuscrito da mesma. Por outro lado, Jean Rott atribui a anotação de Bucer "Grammatica hebraea, uno libro" ou a Wolfgang Capito, Johannes Reuchlin ou a François Tissard (BCor 1, 54, n. 41); GRESCHAT, 1976, p. 42, nota 72 considera que Capito tenha possuído Hebraicarum institutionum Libri duo (Basel 1518) como sendo pouco provável.

11 GRESCHAT, Martin. Martin Bucers Bücherverzeichnis von 1518. In: Archiv für Kulturgeschichte, 57, p. 162-185, 1975. aqui p. 184. 
Após a saída da ordem dos dominicanos e de dois anos turbulentos, em que também aconteceu o matrimônio com Elisabeth Silbereisen, Bucer se firmou em Estrasburgo. Assim se estabeleceu uma proximidade teológica com o reformador de $\mathrm{Zu}$ rique, Ulrico Zwínglio, junto com o qual participou do "debate religioso" com Martim Lutero em Marburgo. Isso merece atenção especial, porque Bucer parece ter causado uma impressão que se perpetuou ao longo do tempo sobre o conde Felipe de Hesse. O mais tardar a partir de 1538, Bucer passou a contar entre os conselheiros mais próximos do conde. ${ }^{12}$ Como tal e sob sua incumbência participou decisivamente como "Pai da Igreja em Hesse"13 na elaboração do "regulamento de disciplina" de Ziegenhain e no "conselho sobre os judeus". Após o debate religioso de 1529 e a morte prematura de Zwínglio em Kappel (1531), Bucer tornou-se um dos porta-vozes dos reformadores até a Reforma sofrer um forte revés político após a guerra de Esmalcalde de 1547. Nem bem dois anos após, Bucer fugiu de Estrasburgo, refugiando-se em Cambridge, onde veio a falecer em 28 de fevereiro de 1551.

Nas três décadas entre a saída da ordem dos dominicanos e sua morte, Bucer redigiu uma ampla obra literária, desde comentários bíblicos (entre outros, sobre os Evangelhos de Mateus e de João, Carta aos Romanos, Salmos e Sofonias) e textos dogmáticos no espírito de um tomismo protestante, bem como escritos políticos, ordens da vida eclesiástica e cartas. Em diversos desses textos encontram-se manifestações sobre os judeus e o judaísmo. Essas manifestações, em amplos trechos, aparecem como eco da tradição cristã desde Agostinho até Tomás de Aquino. ${ }^{14}$

$\mathrm{Na}$ criação literária de Bucer parece ocorrer uma ruptura em torno do ano de 1530. Até essa data, Bucer redigiu a maioria dos comentários bíblicos, nos quais, como veremos a seguir, se pode perceber um acolhimento positivo, mas ao mesmo tempo crítico da língua hebraica e do judaísmo. Posteriormente, com exceção do comentário à Carta aos Romanos, a recepção se desloca mais para reflexões jurídicas, possivelmente motivadas por sua atuação político-eclesiástica.

O ano de 1530 representa para a Reforma na Alemanha, sob o ponto de vista político, uma ruptura. Basta lembrar a dieta de Augsburgo, em que o movimento da Reforma se apresentou com uma confissão própria e, ao mesmo tempo, Josel von Rosheim, como representante dos judeus alemães, se distanciava radicalmente da Reforma. ${ }^{15}$ Também em relação à cidade de Estrasburgo essa data é significativa, uma vez que no dia 16 de março o senado da cidade emitiu um decreto em que se fazia re-

12 Cf. na introdução do editor: Briefwechsel Landgraf Philipp's des Grossmüthigen von Hessen mit Bucer. Editado e comentado por Max Lenz. Leipzig: Hirzel, 1880. 1. Theil, p. v-vi.

${ }^{13}$ Cf. ORTMANN, Volker. Martin Bucer als Kirchenvater Hessens. In: FÄCKE, Bodo (org.). Die Homberger Synode von 1526. Die Reformation in Hessen. 2. ed. Homberg; Efze: Geschichtsverein, 2002. p. 76-85.

14 Em relação a isso, cf. HOOD, John Y. B. Aquinas and the Jews. Philadelphia/PA: University of Pennsylvania Press, 1995.

${ }^{15}$ Quanto à postura de Josel von Rosheim na dieta de Augsburgo, cf. ainda FEILCHENFELD, Ludwig. Rabbi Josel von Rosheim: Ein Beitrag zur Geschichte der Juden in Deutschland im Reformationszeitalter. Strassburg, 1898. p. 27-33, 54s, 117-119, 153-159. (Anexo III). 
ferência à proibição de juros e usura para os judeus. ${ }^{16}$ No entanto, o problema da usura continuou o que fica comprovado pelo fato de que, no dia 13 de setembro de 1539 , foi emitido um novo decreto, a fim de regulamentar a questão dos juros. ${ }^{17}$ Além disso, segundo a opinião de Osten-Sacken, o escrito polêmico Der gantz Jüdisch glaub de Anton Margarith, um judeu convertido ao cristianismo, parece ter tido influência extremamente negativa não apenas em Martim Lutero, mas também em Martin Bucer. ${ }^{18}$

\section{Judeus e judaísmo na obra de Bucer}

Em pesquisas mais recentes, em especial de Peter von der Osten-Sacken ${ }^{19} \mathrm{e}$ Achim Detmers, o comentário aos Romanos de Bucer é analisado como base para o conselho em relação aos judeus de 1538. Detmers classifica o comentário como uma "doutrina sobre Israel" de Bucer, doutrina essa que seria comprovável ao longo de toda a sua atuação. ${ }^{20}$ Já a análise de R. Gerald Hobbs segue um outro caminho. Ele parte do enfoque no comentário sobre os Salmos, em que ele analisa o uso por parte de Bucer de fontes judaicas e da língua hebraica, bem como o seu convívio com contemporâneos judeus. Hobbs destaca que o interesse primordial de Bucer no estudo do hebraico era o sentido literal da Bíblia. Nisso também era possível entrar em debate com estudiosos judeus, motivo pelo qual Rashi ${ }^{21}$, Abraham ibn Ezra ${ }^{22}$ e David Kimchi seriam citados seguidamente no comentário sobre os Salmos. No entanto, judeus contemporâneos podem simultaneamente representar um problema, explicável a partir de uma tese condenatória derivada da Bíblia. ${ }^{23}$ Nesse modo de pensar Hobbs se encontra na sequência de August Lang ${ }^{24}$ e Walter Holsten ${ }^{25}$.

A seguir, procuraremos acompanhar em alguns exemplos essa trilha. Primeiramente, analisaremos o uso da língua hebraica e as descobertas feitas a partir do hebraico; depois descreveremos o aproveitamento de autores judeus em um de seus

${ }^{16} \mathrm{O}$ decreto consta em GLASER, Alfred. Geschichte der Juden in Strassburg. Von der Zeit Karls d. Gr. Bis auf die Gegenwart. Strassburg, 1894. p. 26.

${ }^{17}$ GLASER, 1894, p. 26.

${ }_{18}$ Cf. OSTEN-SACKEN, Peter von der. Martin Luther und die Juden: Neu untersucht anhand von Anton Margarithas „Der gantz Jüdisch glaub“ (1530/31). Stuttgart: Kohlhammer, 2002.

19 OSTEN-SACKEN, 2002, p. 248-253.

${ }^{20}$ DETMERS, Achim. Reformation und Judentum. Israel-Lehren und Einstellungen zum Judentum von Luther bis zum frühen Calvin. Stuttgart: Kohlhammer, 2001. p. 185-215.

${ }^{21}$ Rashi já fora aproveitado por Nikolaus von Lyra, mas parece que Bucer se baseia em estudos próprios.

${ }^{22}$ Sem dúvida alguma, é surpreendente, com base nas edições de textos hebraicos, que textos de Ibn Ezra já muito cedo estavam acessíveis em versões em francês antigo e, posteriormente, em latim. Em parte ele mesmo formulava em latim.

${ }^{23}$ Cf. HOBBS, R. Gerald. Bucer, the Jews, and Judaism. In: BELL, Dean Phillip; BURNETT, Stephen G. (Org.) Jews, Judaism, and the Reformation in Sixteenth-Century Germany. Leiden: Brill, 2006. p. 137169 , onde ele faz um resumo provisório de seus estudos anteriores.

${ }^{24}$ LANG, A[ugust]. Der Evangelienkommentar Martin Butzers und die Grundzüge seiner Theologie. Leipzig: Dieterich, 1900.

${ }^{25}$ HOLSTEN, Walter. Christentum und nichtchristliche Religion nach der Auffassung Bucers. Theologische Studien und Kritiken: Eine Zeitschrift für das gesamte Gebiet der Theologie, v. 107, Neue Folge II, p. 105-194, 1936. 
comentários bíblicos e, finalmente, lançaremos o olhar, com base nessa análise, nos escritos políticos de Bucer.

\section{O manejo da língua hebraica}

A partir da segunda metade dos anos 20 do século XVI, Bucer redigiu diversos comentários bíblicos. Em Estrasburgo, ele mesmo organiza seus escritos em um conjunto de comentários, uma vez que ele e Wolfgang Capito teriam decidido organizar um projeto de comentários, sendo que Bucer comentaria os escritos do Novo Testamento e Capito, os do Antigo Testamento. ${ }^{26}$ No início, consta um comentário sobre o Evangelho de Mateus, que inclui também explicações de textos paralelos dos outros sinóticos - Marcos e Lucas. ${ }^{27}$ Segue um comentário sobre Efésios (igualmente de 1527) e uma interpretação do Evangelho de João $(1528)^{28}$. Após uma pausa de alguns anos, surgiu em 1536 um comentário muito extenso sobre a Carta aos Romanos. ${ }^{29}$ Além disso, constam dois comentários sobre escritos veterotestamentários: sobre o profeta Sofonias $(1528)^{30}$ e sobre os Salmos $(1529)^{31}$. Importante no manejo, tanto do

${ }^{26}$ Cf. O prefácio de Bucer ao comentário sobre o Evangelho de Mateus em LANG, 1900, 378 (= Ennarationvm in Evangelia, 1527 [veja nota seguinte], f. 3a).

${ }^{27}$ Nas minhas pesquisas eu me basei na edição Enar/rationvm in Evan/gelia Matthcei, Marci, \& Lucce, / libri duo. // Loci communes syncerioris Theologice / supracentum, ad simplicem scriptu/rarum fidem, circa ullius infecta/tionem aut criminationem, / excußi, / per M. Bucervm. / Argentorati, Anno, M.D.XXVII. [Universitäts- und Landesbibliothek Bonn (= ULB BN) Gk 115]. Esse título, no entanto, só deixa transparecer a apreciação de Mateus 1-7. O segundo volume muito raro da primeira edição não estava acessível durante a elaboração do presente estudo.

${ }^{28} \mathrm{O}$ comentário de João, numa edição crítica, consta em BOL 2: Enarratio in Evangelion Iohannis (1528, 1530, 1536), publicado por Irena Backus. Leiden et alii: Brill, 1988. A edição de 1530 contém, além disso, a segunda edição do comentário de Mateus, do qual ainda não há uma edição crítica. O comentário da Carta aos Efésios só é acessível em sua primeira edição e não foram feitas reedições.

${ }^{29} \mathrm{O}$ comentário ainda não existe em edição crítica. A seguir baseio-me na seguinte edição: Metaphrases et / enarrationes perpetvae epistolarvm / D. Pauli Apostoli, quibus singulatim Apostoli omnia, / cum argumenta, tum sententice \& uerba, ad autori/tatem D. scripturce, fidemq(ue) Ecclesice catho/lica tam prisca quàm prcesentis, religiose / ac paulo fusius excutiuntur. // Dissidentivm in speciem locorvm scri/ pturce, \& primarum hodie in religionis doctrina con/trouersiarum conciliationes \& decisiones. XLII. // [...] // Tomvs Primvs. / continens metaphrasim et enarrationem / in Epistolam ad Romanos, in qua ut Apostolus prccipuos totius Theologice / locos tractauit quàm exactissime \& plenissime, ita est hoc Tomo maxima / pars totius non tam Paulince, q(uam) uniuers(a)e S. Philosophi(a)e explicata. / per Martinvm Bvcervm. // Argentorati per VVendelinvm / Rihelium. Mense Martio. Anno / M. D. XXXVI. [ULB BN $\left.4^{\circ} \mathrm{Ga} 1279\right]$.

${ }^{30}$ Tzepha/niah, qvem Sopho/niam, uulgo uoca(n)t, prophetarum / epitomographus, ad ebraicam / ueritatem uersus, \& com/mentario explanatus / per M. Bucerum // Argentorati apvd Ioannem Hervagi/vm, mense sept. / anno M. D. / XXVIII.

${ }^{31}$ A seguir, citações segundo a 4. ed.: Sacrorvm Psal-/morvm libri qvinqve, ad ebrai-/cam veritatem genvina / uersione in Latinum traducti: primum appensis bona fide sententijs, / deinde pari diligentia adnumeratis uerbis, tum familiari / explanatione elucidati. // Nunc denuo, non paulo maiore quam antea, \& fide \& di-/ ligentia emendati. // Aretio Felino / autore. / [...] / Basileæ per Ioan. Heruagium 1547 [ULB BN $4^{\circ}$ Ga 702]. 
Antigo quanto do Novo Testamento, é o princípio hermenêutico básico de que há uma unidade indissolúvel entre os testamentos e da aliança de Deus. ${ }^{32}$

Tomando-se todos os comentários sobre escritos do Novo Testamento em conjunto, cai na vista que Bucer interpreta nomes e textos neotestamentários recorrendo ao hebraico. De que forma - isso nós iremos demonstrar exemplarmente com base na introdução do comentário de Mateus. Aí Bucer expõe que, o que na literatura cristã é designado por "evangelho", no hebraico, é traduzido por besorah, que, por sua vez, provém de basar. Esse verbo é utilizado pelos profetas para prenunciar a profecia da graça, que será revelada pelo Cristo. Na Septuaginta, esse verbo sempre é reproduzido por evangelizein. Isso Bucer fundamenta com base em diversos textos dos Salmos e do profeta Isaías. ${ }^{33}$

Mas Bucer também interpreta outros termos a partir do hebraico; por exemplo, que "Cristo", como designação do futuro rei, deriva do termo hebraico משיח que, por sua vez, é reproduzido no grego por $\chi \rho \iota \sigma \tau o ́ \varsigma^{34}$. O nome da cidade de origem de Jesus Nazaré (que deriva de נזיר e não de - é também explicado detalhadamente ${ }^{35}$, bem como de onde derivam os termos "escribas" (סופרים), "מורשים (de) e "saduceus" (ציקדיקים tário de João, são as dos termos "torá" 37 e "filhos do trovão" ${ }^{38}$. Mas também se pode observar certo desenvolvimento teológico. Enquanto no comentário dos evangelhos (sinóticos) Jesus = יהושע é derivado de, filologicamente correto, da raiz do hifil no comentário de João, é acrescentada uma derivação do nome de Deus mentário de Romanos, concluído em 1536, Bucer aplica, a partir de uma perspectiva filológica humanista, o mesmo procedimento de explicar termos gregos (e latinos) a partir do hebraico, justificando esse procedimento com o fato de que Paulo se referia a termos e temas hebraicos. Assim, por exemplo, como no comentário de João, o nome Jesus é identificado com o tetragrama. ${ }^{41}$

Para avaliar a relação teológica de Bucer com o judaísmo, o comentário de Romanos serviu de base para diversas análises, de maneira que, neste momento, basta

32 Ennarationvm in Evangelia, 1527, 150v-159r, citado e traduzido em partes em DETMERS, 2001, p. 197 (segundo a 3. ed. de 1536). - Nur noch fragmentarisch erhalten und bereits im 16. Jahrhundert posthum veröffentlicht sind zudem Vorlesungen über das Richterbuch. Estão preservadas apenas fragmentariamente e já foram, postumamente, publicadas no século XVI também preleções sobre o livro de Juízes I, sobre isso cf. TIMMERMAN, Daniel. Martin Bucer as Interpreter of the Old Testament: A Re-examination of Previous Scholaship in Light of Bucer's Ennarationes in librum Iudicum (ca. 1540). In: Reformation and Renaissance Review, v. 9, p. 27-44, 2007.

33 Ennarationvm in Evangelia, 1527, p. 1r.

34 Cf. Ennarationvm in Evangelia, 1527, p. 9v.

35 Cf. Ennarationvm in Evangelia, 1527, p. 39r-40r.

${ }^{36} \mathrm{Cf}$. Ennarationvm in Evangelia, 1527, p. 159r-160r.

${ }_{37}$ Cf. Ennarationvm in Evangelia, 1527, p.148v. BACKUS, 1988, p. 349.

${ }^{38}$ Cf. BUCER, 1527, p.125r-v; BACKUS, 1988, p. 17.

${ }^{39}$ Cf. BUCER, 1527, p.15r-16r, no caso, p. 15v.

${ }^{40}$ Cf. BACKUS, 1988, p. 25s, 221.

${ }^{41}$ Cf. BUCER, 1530, p. 11b, 64b, 195a-197a. - Com relação à alteração no método exegético de Bucer, cf. LANG, 1900, v.a. 31s. 
vermos um resumo dessa análise. ${ }^{42}$ Por um lado, vale também para Bucer o tradicional argumento de que, com a encarnação de Jesus, a igreja substituiu Israel. ${ }^{43}$ Consequentemente, considerando também o secreto desígnio de Deus, os judeus estão rejeitados. ${ }^{44}$ Mas como Israel é o povo escolhido de Deus, uma parte do povo, ou seja, os crentes serão salvos, no final dos tempos, junto com a igreja crente, formando assim o verdadeiro Israel. Por outro lado, no entanto, é digno de nota que Bucer, apesar desses preconceitos tradicionais, não deixa de mencionar o tratamento que os judeus recebem na sociedade da época. Assim, ele cita, por exemplo, o tratamento impiedoso e bárbaro dos judeus, a contradição com o direito vigente, os excessivos juros cobrados de judeus que, no entanto, representam, ao mesmo tempo, um poder econômico muito forte. Isso dificulta uma potencial adesão dos judeus ao cristianismo. ${ }^{45}$

\section{Aproveitamento de autoridades judias nos comentários bíblicos de Bucer}

Gerald Hobbs, que se ocupou intensivamente com o comentário sobre os Salmos, mostrou que Bucer não tinha escrúpulo nenhum em citar autoridades judias na interpretação dos Salmos. Em primeiro lugar, trata-se do targum ${ }^{46}$, Rashi (por volta de 1040-1105) ${ }^{47}$, Abraham ibn Ezra (1089-1164) ${ }^{48}$ e David Kimchi (por volta de 1160-1235 ${ }^{49}$. Além disso, aparecem no comentário dos Salmos nomes como Flavio Josefo $^{50}$, diversos rabinos da mishnah e do talmude, entre eles Yehuda ha-Nasi (Rav), o redator da mishnah ${ }^{51}$, Saadya Gaon ${ }^{52}$, Joseph Kimchi, o pai de David Kimchi ${ }^{53}$, e um rabino Moses que, noutro momento, é designado como Moshe Cohen ${ }^{54}$, que, no entanto, também poderia ser Moshe ha-Darshan ou Maimonides ${ }^{55}$. Conforme Hobbs, para a elucidação do sentido literal, Bucer seguidamente se associa às interpretações

${ }^{42}$ Cf. DETMERS, 2001, p. 185-215.

${ }^{43}$ Veja, por exemplo, BUCER, 1530, p. 192a. No entanto, essa ideia já é exposta em momentos anteriores, como, por exemplo, em "Bericht auß der heyligen geschrift". In: STUPPERICH, Robert (ed.). Straßburg und Münster im Kampf um den rechten Glauben 1532-1534. Gütersloh, 1978. (BDS 5). p. 109-258, aqui p. 178,37-179,5. 180,34-184,20.

${ }^{44}$ BUCER, 1530, p. 426b.

${ }^{45}$ BUCER, 1530, p. 442b.

${ }^{46}$ Sempre sob o nome Joseph Paraphrastes Chaldeus, ao total, em 76 passagens.

${ }^{47}$ São 41 passagens.

${ }^{48}$ Mais de 100 menções.

${ }^{49}$ Mais de 150 menções.

${ }^{50}$ BUCER, 1547, p. 33, 107, 156, 246, 318s, 392, 403, 439, 559, 610.

${ }^{51}$ BUCER, 1547, p. 521; outros rabinos são o amorreu R. Jonah (por volta do séc. IV, p. 340) e R. Levi (por volta dos séc. II/III, p. 259), bem como, em uma passagem, o autor da massorá, provavelmente um dos tiberíades da família dos Bney Asher (a partir do séc. VIII, p. 320).

${ }^{52}$ BUCER, 1547, p. 482.

${ }_{53}$ BUCER, 1547, p. 90, 130, 336, 453, 573.

${ }^{54}$ BUCER, 1547, p. 96 . As três outras menções de um rabino Moshe encontram-se na p. 475, p. 519, p. 573.

${ }^{55}$ Com relação à dificuldade de classificação precisa dos nomes, cf. HASSELHOFF, Görge K. Dicit Rabbi Moyses: Studien zum Bild von Moses Maimonides im lateinischen Westen vom 13. bis zum 15. Jahrhundert. 2. ed. Würzburg: Königshausen \& Neumann, 2005. p. 16, 21. 
de Ibn Ezra e de Kimchi, enquanto Rashi serve mais como exemplo negativo, do qual Bucer se distancia. ${ }^{56}$ Ele também o justifica na introdução ao comentário. ${ }^{57}$

Vejamos um exemplo. No Sl 110.4 é dito a respeito do rei/messias: "Tu és sacerdote para sempre, segundo a ordem de Melquisedeque”. Na Carta aos Hebreus, esse anúncio é entendido como promessa feita para Jesus (cf. Hb 5-7). Em seu comentário, Bucer procura elucidar o sentido literal dessa passagem. Para tal ele menciona inicialmente Kimchi, que interpreta a passagem no sentido de que a ordem divina em relação ao sacerdócio é expressão do primado (princeps) soberano e do reinado eterno do mesmo. Assim, a expressão al divrati significa que, caso ele queira ser um rei da justiça, ele deve zelar por direito e justiça para todo o povo. Ibn Ezra, no entanto, interpreta a expressão al divrati como costume e rito de Melquisedeque. Com isso estaria sendo dado um exemplo de como, assim como Abraão dera uma parte de seu despojo para Melquisedeque, o povo ofertara a Davi o despojo (em forma de armas) que conquistara dos inimigos. Por sua vez, Rashi interpreta a passagem no sentido de que Davi seria semelhante a Melquisedeque, porque ambos seriam sacerdotes e governantes do Altíssimo. A Carta aos Hebreus, por sua vez, interpretaria a passagem no sentido de que quem não conhece a Cristo, na realidade não entenderia coisa alguma corretamente. Por isso a expressão divrati só estaria repetindo o que já fora expresso com o termo malki (meu rei) que consta no nome Melquisedeque. Exemplos semelhantes se encontrariam seguidamente na Escritura. ${ }^{58}$

Considerando o contexto amplo do comentário dos Salmos, cai em vista que Bucer não o publicou em seu próprio nome, nem na primeira edição, nem na edição de 1547, mas o fez sob o pseudônimo Aretius Felinus. Como nos demais comentários bíblicos raramente aparecem autoridades judias, causa a impressão de que o representante da Reforma e autoridade da igreja Martin Bucer não poderia se dar ao luxo de citar autoridades judias, enquanto que o humanista o podia fazê-lo sem problema sob o pseudônimo. Mesmo assim, há também nos comentários do Novo Testamento muito esporadicamente referências a autoridades judias. Como exemplo, vejamos a seguinte passagem. Em Rm 3.13, Paulo cita o S1 140.4. Ali se trata de עכשוב de Romanos esse termo é explicado mediante recurso à explicação da referida passagem no comentário dos Salmos. Aí Bucer/Felinus havia explicado que Rashi reproduz o referido termo com a palavra do francês antigo para aranha, Ibn Ezra e Kimchi, ao contrário, dizem que se trata de uma besta muito cruel e feroz. ${ }^{60}$ No comentário de Romanos consta o seguinte:

${ }^{56}$ Cf. HOBBS, R. Gerald. Martin Bucer on Psalm 22: A Study in the Application of Rabbinic Exegesis by a Christian Hebraist. In: FATIO, Olivier; FRAENKEL, Pierre (Orgs.). Histoire de l'exégèse au XVIe siècle: Texte du colloque international tenu à Genève en 1976. Genebra: Droz, 1978. p. 144-163, à p. 150s; HOBBS, 2006, p. 141-154.

57 BUCER, 1547, Prefatio f. [a6r].

${ }^{58}$ Cf. BUCER, 1547, p. 521.

59 Esse termo hebraico, que só aparece nessa passagem (hapaxlegomenon), é de difícil tradução.

${ }^{60}$ Cf. BUCER, 1547, p. 589. 
[Há] veneno de áspides debaixo dos lábios deles. Assim afirma S1 140[.4]: e isso significa o que está acima, qual seja, a culpa, como foi dito, e ele pensa nos crimes nefastos, através dos quais [os] ímpios subitamente destroem [os] inocentes No hebraico [do salmo] consta עכשוב, que Rabi Schlomoh [= Rashi] traduz por "aranha", porém mais adequado [é] que, através desse nome, seja designado [um animal] de culpa extraordinária e de veneno mais eficaz com esse nome, pois neste verso o profeta [= Davi] prometeu uma serpente ${ }^{61}$.

Portanto, Bucer aproveita a explicação de Rashi para o termo hebraico עכשוב. No entanto, ao mesmo tempo se distancia dessa explicação e contrapõe a sua própria que, por um lado, tem semelhança com a explicação de Kimchi e Ibn Ezra (noxa); por outro lado, porém, apresenta uma ampliação (serpens). No entanto, importa ter presente o seguinte: Ele não hesita em recorrer à autoridade de Rashi.

Outra pergunta que se impõe é a de onde Bucer tem todo esse conhecimento de autores judeus. Uma possibilidade seria a de que ele teria assumido coleções de textos medievais como, por exemplo, a Postilla de Nicolaus von Lyra ou o Pugio fidei de Ramon Martí. No entanto, dessas fontes só seria possível o conhecimento de Rashi. Outra possibilidade para o conhecimento do targum é o Psalterium Octaplum de Agostino Giustiniani, onde o texto dos Salmos é reproduzido em hebraico, grego, árabe (!) e aramaico. ${ }^{62}$ E a possibilidade de conhecimento de Rashi, Kimchi e Ibn Ezra é a Biblia Rabbinica de 1517, respectivamente na Bomberg-Edition de 1524/2563.

\section{O tratamento de judeus em escritos políticos}

Bucer não foi apenas teólogo, ele também foi político eclesiástico. ${ }^{64}$ Assim, diversas vezes foi desafiado a redigir regimentos de igreja e ordens da vida eclesiástica. Além dos escritos que serão analisados a seguir, basta mencionar o regimento da arquidiocese de Colônia ${ }^{65}$, que nunca foi implantado, bem como o escrito De regno Christi $^{66}$, tão importante para a Reforma inglesa.

${ }^{61}$ Venenum aspidu(m) sub labijs eorum. Hoc Psalmus habet .140 . \& ualet ide(m) q(uod) superiora, noxias e(ni)m eo dicto \& exitiales intelligit fraudes, quibus impij innocuos subito euertunt. Hebraice est עכשוב quod Rabi Schlomoh aranea(m) uertit, sed uerisimilius est p(re)cipu(a)e nox(a)e \& prcesentioris ueneni animal hoc nomine significari, na(m) uates serpente $(m)$ p(ro)misit eode $(m)$ uersu. BUCER, 1530, p. $173 b$.

${ }^{62}$ Psalterium Hebreum, Graecum, Arabicum, Chaldaicum: cum lat. interpr. / cum tribus latinis interpretationibus et glossis Augustini Justiniani. Genua: Porrus, 1516. (O Saltério é facilmente acessível em $<$ http://gallica.bnf.fr>.).

${ }^{63}$ Cf. HOBBS, 1984, p. 486s.

${ }^{64}$ Cf. a consistente coletânea STROHM, Christoph (Org.). Martin Bucer und das Recht: Beiträge zum internationalen Symposium vom 1. bis 3. März 2001 in der Johannes a Lasco Bibliothek Emden. Genebra: Droz, 2002.

${ }^{65}$ Cf. Schriften zur Kölner Reformation. Teil 1.: STROHM, Christoph; WILHELMI, Thomas; BUCKWALTER, Stephen E. (ed.). Gütersloh, 1999. Teil 2: WILHELMI, Thomas (ed.). Gütersloh, 2003. (BDS 11/1-2).

${ }^{66}$ BUCER, Martin. De regno Christi. Libri Dvo 1550. Organizado por François Wendel. Paris; Gütersloh: GVH, 1955. (BOL 15). 
Dialogi (1535)

Referente ao enfoque em judeus, significativos são os Dialogi de Bucer, que surgiram em 17 de maio de 1535 com dedicatória ao senado da cidade de Augsburgo ${ }^{67}$ Nesses diálogos (fictícios), três oradores discutem a respeito do papel da autoridade numa cidade-estado da Reforma. Hartmut representa o entusiasmo religioso zwingliano; Sinnprecht defende a posição indecisa humanista de Sebastian Franck e Fridlieb aparece como mediador com características da posição de Bucer. No sétimo diálogo (dentre nove), Fridlieb, ou seja, Bucer constata:

Falta-nos fé, caro irmão. Com palavras confessamos a Deus, mas com ações nós o negamos. Caso contrário, poderíamos, por causa do nome do Senhor, entregar, negar tudo ao nosso redor. Sim, odiar nossa esposa e filhos, pai e mãe, irmã e irmão e nossa própria vida. Haveria também um pouco do entusiasmo, que marcava os levitas, pois dedicavam suas mãos ao Senhor, podendo matar a seu filho e irmão, a fim de evitar que renegassem a fé em favor do bezerro de ouro e, assim, alcançavam a bendição de Deus diante das outras tribos de Israel, entusiasmo esse que Fineias demonstrou diante da tribo de Simeão. O mesmo entusiasmo de Elias diante dos sacerdotes de Baal, de Jeú, de Ezequias e de Josias contra toda a idolatria que havia se infiltrado entre seus antepassados no povo de Deus ${ }^{68}$.

O entusiasmo da fé em Israel é exemplar. E, na sequência do diálogo, Bucer destaca que, pela causa do evangelho, se faz necessário aplicar uma dose forte de remédio. ${ }^{69}$ No entanto, em relação a Israel, vale que só foi necessária uma única dose, ou seja, por ocasião da peregrinação pelo deserto. Porém, para os judeus e cristãos descrentes, deve-se continuar a ministrar o remédio por um período muito mais longo:

Tamanhas maravilhas, como Deus fizera a Israel no deserto, nunca mais o fez ao povo de Israel nem a nenhum outro povo. Israel era para ser naquela época e também depois um povo exemplar e modelo para todo o mundo (1Co 10.6). Para aprender nele como Deus trata a ambos: os que o respeitam e os que o desprezam. Pois os mencionados judeus e cristãos, que desprezam o Cristo, recebem de Deus seus pesados e duros castigos e sofrimentos, após a exaltação de Cristo, nosso Senhor. Assim, a última destruição dos judeus foi tão cruel que semelhante dor e sofrimento jamais houve e nunca haverá. Pois os judeus nunca sofreram tanto com egípcios, sírios, assírios, caldeus e outros povos, como os cristãos sofreram semelhantes dores de persas, godos, francos, turcos e outros povos. Os judeus permaneceram setenta anos no exílio babilônico. Assim são quase novecentos anos que se iniciou a destruição das igrejas cristãs por Maomé. E

${ }^{67}$ BUCER, Martin. Dialogi oder Gesprech: Von der gemainsame vnnd den Kirchen pbungen der Christen Vnd was yeder Oberkait von ampts wegen auß Gýttlichem befelch an den selbigen zůuersehen vnd zů besseren gebüre“ (1535). In: STUPPERICH, Robert (Org.). Zum Ius Reformationis: Obrigkeitsschriften aus dem Jahr 1535. Dokumente zur 2. Straßburger Synode von 1539. Gütersloh: GVH, 1984. (BDS 6,2). p. 39-188.

${ }^{68}$ BUCER, 1984, p. 117,36 - 118,9.

${ }^{69}$ Cf. BUCER, 1984, p. 119,6-13. 
desde lá só aumentou o sofrimento, não só na Palestina, onde os judeus moravam, mas por toda a Síria, Ásia, Grécia, Egito e África. Todas essas regiões foram privadas do santo Evangelho com indizíveis destruições. E por isso também nunca faltaram pestes e carestias. Como fora no início da divulgação do Evangelho quando, sob o imperador Cláudio, houve tamanha carestia que se fez em todas as regiões coletas em favor dos santos na Judeia ${ }^{70}$.

No entanto, o castigo do povo não é um fim em si mesmo, mas tem caráter de medida pedagógica. "Por isso Deus castigou sempre a maldade mais fortemente nos judeus do que nos pagãos, nos cristãos mais severamente do que nos judeus e nos pagãos" ${ }^{\prime 71}$. Logo, a dádiva dos mandamentos a Moisés foi uma grande graça ${ }^{72}$, ou seja, como presente do Espírito de Cristo:

Evidentemente o Espírito de Cristo, que instruíra o povo de Israel para avaliar corretamente uma mensagem, este mesmo espírito certamente também instruirá um príncipe cristão para encaminhar tudo da melhor forma para o bem, antes de exercer o forte castigo $^{73}$.

Se até esse ponto Israel ainda deve ser visto tipologicamente, sendo a igreja a continuidade lógica do agir salvífico de Deus, com a encarnação de Jesus Cristo iniciou-se um novo tempo. E, a partir desse momento, os judeus fazem parte daqueles que foram rejeitados. Logo - e isso é surpreendente em Bucer - vale no reino a lei romana. Correspondente a isso, num momento posterior do diálogo, Fridlieb aponta para a questão do direito:

Mas quando chegou a hora e a oportunidade, eles reconheceram ser útil para tal finalidade o castigo que então estabeleceram: privação de alimento, de honra e de todo e qualquer convívio humano no reino. No livro sobre hereges e maniqueus e samaritanos, apóstatas, judeus e adoradores do céu, sobre sacrifícios pagãos e templos ${ }^{74}$.

Uma apostasia do Deus (cristão) é equivalente à apostasia "da fé em direção aos judeus ou aos pagãos"75.

Os diálogos também evidenciam que o Israel veterotestamentário possui forte caráter de exemplo. Esse, no entanto, foi superado no momento em que se fundou a igreja. Assim, a religião judaica perde, ao menos em parte, o status da graça (por ter negado a Deus) e passa a ser uma grandeza do direito comum.

\footnotetext{
${ }^{70}$ BUCER, 1984, p. 120,19-38.

71 BUCER, 1984, p. 121,6-8.

${ }^{72}$ Cf. BUCER, 1984, p. 122,9-18.

${ }^{73}$ BUCER, 1984, p. 122,30-34; cf. p.160,33-161,2. - p.142,7-18 fica evidente que a lei permanece válida também para cristãos, uma vez que ela ensina ,das übel [... zu] hassen “ (1.10).

74 BUCER, 1984, p. 138,13-17; Complementações por parte de Stupperich, o qual aponta para o Corpus Iuris Civilis, Cod. I,5-11 como fonte do direito. In cod[ice] de here[ticis] et ma[nichaeis et samaritis], de Aposta[tis], De iud[aeis] et coel[icolis] de sacri[ficiis] pa[ganis] et temp[lis].

75 BUCER, 1984, p. 150,32.
} 
Com isso estão estabelecidas as coordenadas para posteriores manifestações de Bucer, entre elas, o "Conselho sobre os judeus", de 1538.

O "Conselho sobre os judeus", de 1538

O conselho, "Se a autoridade cristã esteja autorizada a permitir que judeus morem entre cristãos e, caso venha a permitir de que forma e tudo o mais" "76, que Bucer redigiu juntamente com seis clérigos de Hesse, não tem apenas em relação à teologia de Bucer uma longa pré-história, mas também um efeito posterior.

\section{Pré-história}

No dia 28 de julho de 1524, o conde Felipe de Hesse expulsara os judeus de seu território. No entanto, a maior parte da população judia parece ter permanecido no território. Assim, em 28 de maio de 1532, Felipe editou novo salvo-conduto para os próximos seis anos. ${ }^{77}$ Ao final desse período de seis anos, Felipe incumbiu sua chancelaria de solicitar um parecer sobre o tratamento a ser dado aos judeus. Como Bucer se encontrava desde outubro em Hesse, a fim de ajudar como consultor e orientador na questão do batismo, o senado da cidade de Estrasburgo sugeriu o seu nome também para essa questão. Aos conselheiros teológicos foi apresentada uma proposta de texto, com sete artigos, "Conselho como os judeus devem ser tolerados" origem é difícil de ser explicada. Parece que as primeiras cinco teses sobre economia poderiam se originar de sugestões dos próprios judeus de Hesse, uma vez que apresentam grande semelhança com os princípios defendidos por Josel von Rosheim na dieta de Augsburgo de 1530. A origem das outras duas teses (ordem sobre a pregação e a proibição de debate) permanece incerta.

\section{O conselho}

A resposta à solicitação de Felipe, de dezembro de 1538, contém sete assinaturas. Além de Bucer, assinam seis superintendentes e pastores. Mesmo assim, há a suspeita de que Bucer seja o autor principal do conselho, uma vez que os teólogos de Hesse, ao que parece, defendiam uma extradição de todos os judeus. ${ }^{79}$ No detalhe, as sete teses são comentadas de forma detalhadamente diferenciada, destacando-se em especial a ênfase nos aspectos econômicos. ${ }^{80}$ No geral, porém, são avaliadas como sendo por demais brandas. Depois de uma consideração introdutória de que tanto a Sagrada Escritura como concílios constataram que judeus não creem conforme a

${ }^{76} \mathrm{O}$ texto consta em BDS 7, p. 342-360(1).

$77 \mathrm{O}$ texto consta em BDS 7, p. 377 (como anexo 1).

${ }_{78}$ BDS 7, p. 342s.

79 Cf. BDS 7, p. 360,1-13.

${ }^{80}$ Para isso já apontara KLEINER, John W. The Attitudes of Martin Bucer and Landgrave Philipp toward the Jews of Hesse (1538-1539). In: LIBOWITZ, Richard (Hg.). Faith and Freedom. A Tribute to Franklin H. Littell. Oxford et al.: Pergamon Press, 1987. p. 221-230, à p. 223-225. 
verdadeira religião, as teses previamente apresentadas são comentadas, em geral, de forma equilibrada. No entanto, alguns detalhes caem imediatamente em vista:

- O talmude, como base para a religião judia, é menosprezado pelos avaliadores, e histórias do talmude são classificadas como sendo enganosas: "Pois através das ateias histórias do talmude os judeus pobres e benevolentes são afastados de nossa verdadeira religião" $"$.

- Sugere-se proibir a construção de novas sinagogas. ${ }^{82}$

- Deve-se introduzir uma proibição de debates sobre questões religiosas em nível inferior a especialistas teológicos. Por outro lado, destaca-se a obrigatoriedade para todos os membros de famílias judias de assistir a pregações cristãs. ${ }^{83}$ (Especialmente nessas recomendações caem em vista as semelhanças para com exigências em relação a famílias anabatistas.)

- Finalmente, com base em Dt 28.43s - o que evidencia um aspecto "novo" sob o ponto de vista teológico -, é sugerido um programa econômico de divisão de trabalho que significa a destruição da base da existência econômica dos judeus em Hesse. Além da proibição do ágio e do comércio em geral ${ }^{84}$, propõe-se que cabem aos judeus: "Os trabalhos mais desprezíveis, pesados e difíceis, tais como mineração, cavar e construir diques, quebrar pedras e rachar lenha, queimar carvão, limpar chaminé e cloaca e coisas semelhantes" $"$. Fundamenta-se essa ideia, com base naquela passagem do Deuteronômio, com o argumento de que os judeus, como sendo os atuais estrangeiros, passaram a ser o rabo, enquanto os cristãos, como os verdadeiramente crentes, passaram a ser a cabeça. ${ }^{86}$

O conselho termina com a sugestão de expulsar os judeus: "Por isso deve-se reconhecer e concluir que tinha que ser mais útil e melhor, assim como a situação está colocada no condado, não tolerar mais os judeus no condado"87.

81 BDS 7, p. 351,26-28. Que Bucer já anteriormente tem reservas ao pensamento rabínico pode-se ver em uma declaração em uma carta aos valdenses do período após 19 de outubro de 1530. (In: BCor 5: (September 1530 - Mai 1531). Hrsg. und bearb. von Reinhold Friedrich u.a. Leiden; Boston: Brill, 2004. [Studies in Medieval and Reformation Thought, v. 101], 43-74 n. 351, aqui 65,6-9).

82 BDS 7, p. 352,1-3. Essa proibição está de acordo com o Codex Justitianus I,9,19.

83 BDS 7, p. 352,4-18.

${ }^{84}$ BDS 7, p. 353,3-5. Que a usura parece ter sido o verdadeiro problema para Bucer pode ser visto no escrito mais antigo „Vom mangel der Religion, an deren alles hanget“ (ca. 1532). Cf. STUPPERICH, Robert (hrsg.). Zur auswärtigen Wirksamkeit 1528-1533. Gütersloh; Paris, 1975. (BDS 4). p. 449-464, aqui p. 458,4-20.

${ }^{85}$ STUPPERICH (hrsg.), 1975, p. 356,9-12. Cf. A sugestão que merece consideração em VOGT, Herbert. Martin Bucer und die Kirche von England. 1966. Tese (Mestrado em Filosofia) - Münster, 1966. p. 92, de que o pensamento de Bucer remontaria ao escrito „Utopia“ de Thomas Mores, no prelo em 1518. De fato sugestões semelhantes de fortes trabalhos físicos dos escravos encontram-se em SURTZ, Edward; HESTER, J. H. (hrsg.). The Complete Works of St. Thomas More. New Haven; London, 1965. v. 4, Buch II, p. 84. No entanto, no melhor dos casos, deve ter sido, para Bucer, apenas uma motivação para a reflexão, porque o "novo" nessas propostas é de fato a fundamentação bíblica.

${ }^{86}$ Cf. BDS 7, p. 353,24-354,27. Essa passagem bíblica passa a ser central para Bucer na continuidade da "questão dos judeus".

87 BDS 7, p. 360,11-13. 


\section{Efeito posterior}

Contrariando as expectativas, o conde não acatou o conselho. Em lugar disso, em 23 de dezembro de 1538, enviou a seus conselheiros um documento de responsável teologia laica, em que ele, com base em seus próprios estudos bíblicos, rechaça as duras atitudes coercitivas. ${ }^{88} \mathrm{O}$ esboço, elaborado no mesmo período, de uma ordem para os judeus, com 11 artigos, acata algumas sugestões do conselho. No entanto, não acolhe as propostas de trabalho forçado e a proibição de comércio. ${ }^{89}$ Já em 27 de dezembro de 1538, Bucer reagiu ao documento do conde..$^{90}$ Nessa carta, ele, por um lado, destaca a posição especial dos judeus na história salvífica; por outro lado, aponta para o problema da falta de fé em Cristo, o que exigiria uma atitude mais severa em relação a eles:

Por isso deveríamos ser tão rigorosos contra os judeus, assim como eles devem ser, a partir do juízo misericordioso de Deus, em relação a todos os descrentes. Mas, na minha opinião, esse povo deveria receber entre nós, por causa dos pais e da eleição, um pouco mais de misericórdia do que outros descrentes. Assim, gostaria de ver que se lhes faça todas as bondades que lhes convêm ${ }^{91}$.

Destacando novamente aquela passagem de Dt 28 , ele também continua a negar a liberdade econômica. No entanto, nos demais artigos, ele concorda com Felipe ${ }^{92}$, inclusive no que diz respeito a uma limitada jurisprudência, "que eles derivam de Moisés e não do talmude" ${ }^{93}$.

A correspondência seguinte de Bucer com Felipe levanta a suspeita de que, com isso, o assunto estaria encerrado. Somente uma única vez ambos fazem referência aos judeus numa observação lateral. Em uma carta de Bucer ao conde de 3 de julho de 1540, encontra-se, num bilhete anexo, a seguinte observação:

Bilhete. Pede por sentimento paternal em relação à nobreza, a qual, como deve ter notado, é contra o chanceler, a quem considera como inimigo. Pede por apoio para o acordo de Sikkingen.

Por causa dos judeus e por causa de outras mazelas, ouça aqueles que não levam vantagem alguma.

Os anabatistas também devem poder voltar. E os pastores devem instar para a disciplina cristã ${ }^{94}$

Na resposta do conde, sem data, possivelmente 12 de julho, consta simplesmente:

\footnotetext{
${ }^{88}$ Veja documento impresso BDS 7, p. 380-382 (como anexo 4).

${ }^{89}$ Veja documento impresso em BDS, p. 383-385 (como anexo 5).

90 A carta está reproduzida em BDS 7, p. 388-390 (como anexo 7).

91 BDS 7, p. 388, 17-19, 22-25.

92 BDS 7, p. 389,20-22.

93 BDS 7, p. 390,6s; cf. p. 385,8-12.

94 LENZ I, p. 178 (n. 69).
} 
Em relação aos judeus em nosso território, tomamos medidas nos últimos dias e esperamos que sejam executadas. O mesmo nós também fizemos em relação aos anabatistas ${ }^{95}$.

No ano de 1539, surge finalmente o decreto de Felipe em relação aos judeus. ${ }^{96}$ Também esse, como os anteriores, parece só ter sido observado em parte. ${ }^{97}$ Como, no entanto, no início de 1539, o "conselho" tinha sido publicado duas vezes ${ }^{98}$, Bucer sentiu-se desafiado a reagir e providenciar, de sua parte, a publicação do mesmo, ao qual ele acrescentou uma carta justificativa a um "bom amigo" no dia 10 de maio de 1539..$^{99}$ Bucer explica na introdução que se trata da consolidação da verdadeira religião, uma vez que existe mais do que só um inimigo de Jesus Cristo:

Os inimigos de nosso Senhor Jesus Cristo, sejam judeus, turcos, papistas ou seja lá como se chamam, irão lutar, blasfemar e causar tanta desgraça, assim como Deus sempre lhes impôs, ao próprio Senhor e também a nós, enquanto permanecerem inimigos de nosso Senhor ${ }^{100}$.

Logo, "a religião dos papistas e dos judeus é um problema"101, especialmente em relação ao culto desvirtuado. ${ }^{102}$ Como os judeus, como filhos de Agar e não de Sara, não representam o verdadeiro Israel, teriam que servir a este. ${ }^{103}$ No entanto, vale em relação aos judeus que eles, na realidade, deveriam ser dominados; porém, considerando Rm 9-11, com misericórdia:

Como o santo Paulo amava os judeus por causa dos pais, assim também nós defendemos que devemos portar-nos em relação a eles de maneira misericordiosa e amistosa. Porém, como são inimigos dos filhos de Deus como do próprio Cristo, eles não devem dominar sobre os filhos de Deus, mas devem servir a eles, assim como Deus ordenou ${ }^{104}$.

Segue uma exposição mais extensa por que, numa perspectiva escatológica, haveria um privilégio do judaísmo frente a outros descrentes, apesar da rejeição. E Bucer conclui:

Em resumo: por causa dos pais e a fim de que o Senhor continue a conceder-lhes a graça, deve-se fazer o bem aos judeus. Porém, de maneira que não cause mal nem a eles nem a outros e que sirva para melhora verdadeira. [...] No entanto, como não ser

95 LENZ I, p. 185 (n. 71).

96 Publicado em BDS 7, p. 391-393 (como anexo 8).

97 Para tal aponta uma carta de admoestação de Felipe de 29 de novembro de 1542 (publicada como anexo 9 em BDS 7, p. 394).

98 Não é possível reconstruir quem assina como responsável pela publicação. Bucer supõe que tenham sido judeus próximos à chancelaria. Cf. BDS 7, p. 362,15,19; p. 365,30s.

99 BDS 7, p. 362-376.

${ }^{100}$ BDS 7, p. 382,25-29; cf. p. 364,34-365,2; 367,33-386,1 e outras mais.

${ }^{101}$ BDS 7, p. 363,10s.

${ }^{102}$ Cf. BDS 7, p. 363s.

${ }^{103}$ Cf. BDS 7, p. 364,28-31 (cf. Gl. 4.22).

${ }^{104}$ BDS 7, p. 369,10-14. 
muito duro ou muito severo, segundo o Evangelho, em relação aos judeus descrentes e a nossos inimigos, não sendo, ao mesmo tempo, muito duro e muito severo em relação aos cristãos crentes, nossos membros em Cristo? ${ }^{105}$

Segue uma justificativa do conselho de Bucer de impor aos judeus trabalhos forçados e de excluí-los do mercado. ${ }^{106}$ Nessa justificativa consta uma observação que dá motivo para a suposição de que Bucer não apenas escreveu a "carta a um bom amigo" por causa da publicação do conselho, mas também porque ele sofrera uma derrota frente a Josel von Rosheim em conexão com a disputa de Frankfurt de fevereiro de 1539. Josel escreve a respeito desse encontro:

[...] e em consequência das disputas que tive diante de muitos sábios de outras nações, a fim de orientá-los, a partir de nossa santa doutrina, contra as palavras de Lutero e de Bucer e seus adeptos, eles me agradeceram pelas palavras de bênção ${ }^{107}$.

Bucer comenta em relação a esse encontro:

[...] um judeu tentou me convencer de que nós lhes teríamos causado grande prejuízo nessa questão [isto é, a sugestão de proibição de comércio]. Então ele me mostrou um livro em que consta que eles devem fazer o bem a nós pagãos, entre os quais eles moram. A isso eu lhe respondi: Nos livros de cristãos e de judeus há muita coisa boa escrita. Mas quando as ações contradizem isso, os livros não desculpam ninguém ${ }^{108}$.

No final da carta, Bucer relembra as tarefas das autoridades, ou seja, exercer a jurisprudência divina e possibilitar a todos os descrentes (e certamente também aos crentes) a possibilidade do arrependimento:

Em resumo: As autoridades exercem o juízo de Deus. Por isso, como Deus, não devem fazer acepção de pessoas, mas considerar a cada um conforme o seu próprio valor. $\mathrm{O}$ Senhor queira conceder a todas as autoridades tal sentimento e boa vontade e a ambos, judeus e maus cristãos, a disposição ao arrependimento. E aos convertidos conceda que com Cristo sempre procurem ajudar a salvar o que está perdido. Amém ${ }^{109}$.

\footnotetext{
${ }^{105}$ BDS 7, p. 373,22-25, 30-34.

${ }^{106}$ BDS 7, p. 373,35-376,7.

${ }^{107}$ ROSHEIM, Josel von. „Journal“. In: KRACAUER, J. Rabbi Joselmann de Rosheim. In: Revue des Etudes Juives, v. 16, p. 82-105, 1888. p. 92 (§ 22); ROSHEIM, Joseph of. Joseph of Rosheim. Historical Writings. Ed. with Introduction, Translations and Indices by Chava Fraenkel-Goldschmidt. Jerusalem 1996. (hebr.). p. 302; versão inglesa in: The Historical Writings of Joseph of Rosheim: Leader of Jewry in Early Modern Germany. Ed. with Introduction, Commentary, and Translations by Chava Fraenkel-Goldschmidt. Translated from the Hebrew by Naomi Schendowich. English Edition ed. and an Afterword by Adam Shear. Leiden; Boston, 2006. (Studies in European Judaism, v. 12). p. 330; cf. FEILCHENFELD, 1898, p. $122,126$.

${ }^{108}$ BDS 7, 375,5-10.

${ }^{109}$ BDS 7, 375,5-10.
} 
A nova publicação do "Conselho" por parte de Bucer, incluindo seus posicionamentos, motivou, por sua vez, uma reação de Josel von Rosheim, redigida em hebraico, que, mais tarde, também foi encaminhada, em tradução para o alemão, para o senado da cidade de Estrasburgo. ${ }^{110}$

No entanto, importa segurar o seguinte: Bucer continuou a se ocupar com a importância teológica de Israel e do judaísmo, porém, sem publicar novos consistentes escritos antijudaicos. Assim, a conclusão de Hastings Eells de 1937 parece continuar a ter certa validade: "Mesmo que Bucer tenha manifestado tão extrema opinião na questão da tolerância dos judeus, é de se duvidar se ele realmente pensava assim no fundo do coração. Antes, parece ser um episódio de menor peso em sua vida" $" 111$.

\section{Conclusão}

Do panorama acima exposto deve ter ficado claro que Martin Bucer, na sua compreensão do judaísmo, parece ter sido jogado para cá e para lá entre humanismo, teologia e política (Realpolitik). Por um lado, dentro da visão tradicional, ele está convencido de que Israel foi substituído pela igreja e que a esperança para Israel consiste unicamente na aceitação de Jesus. Por outro lado, ele ama a língua hebraica e a maneira dos rabinos de buscar o sentido histórico dos textos bíblicos. Ter assumido esse método representou para Bucer muitas críticas, tanto por parte de Conrad Pelli$\operatorname{kan}^{112}$ como de Valentin Crautwald ${ }^{113}$. Diante desse panorama teológico, Bucer não pode deixar de se manifestar politicamente e de se confrontar com a realidade de um judaísmo convicto representado na pessoa de Josel von Rosheim.

Ao proceder dessa forma, Bucer é um "teólogo provocador", como eu afirmara no início? Responder a essa pergunta não é fácil. Bucer não é instigante, mas um teólogo tradicional. Mesmo como reformador ele permanece tomista! ${ }^{114}$ Nessa tradição, ele pode tomar como base a validade permanente do Antigo Testamento para o cristianismo. O povo de Israel, que permanece na aliança, é uma grandeza que tem que fazer parte da reflexão. Os judeus são os irmãos mais velhos que se desviaram e que, por isso, se assemelham aos hereges, mas que, de forma alguma, podem ser identificados com eles. Simultaneamente, Bucer é instigante nas afirmações contundentes, tanto no "Conselho" como carta a um bom amigo, no sentido de que ele parece antecipar aspectos da polêmica vigorosa dos escritos finais de Lutero ou de João Eck. Todavia, ele não conclama a atos de violência, tais como a queima de sinagogas.

\footnotetext{
${ }^{110}$ Cf. ROSHEIM, Joseph of, 1892 (hebr.), p. 328-349; Historical Writings of Joseph of Rosheim, p. 357-363.

${ }^{111}$ EELLS, Hastings. "Bucer's Plan for the Jews". In: Church History, v. 6, p. 127-135, 1937. à p. 135.

${ }^{112}$ Cf. BCor 3: (1527-1529). Editado por Christian Krieger (Org). Leiden et al.: Brill, 1995. p. 310-312, n. 243. (Pellican para Bucer em 6 de agosto de 1529).

${ }^{113}$ Cf. SHANTZ, Douglas H. The Crautwald-Bucer Correspondance, 1528: A Family Feud Within the Zwingli Circle. In: LIENHARD, Krieger. Martin Bucer. v. II, p. 635-643. aqui p. 638-640.

${ }^{114}$ Cf. LEIJSSEN, Lambert. "Martin Bucer und Thomas von Aquin”. In: Ephemerides theologicae Lovanienses, v. 55, p. 266-296, 1979. à p. 288-293.
} 
Finalmente, importa levar em consideração o seguinte: Bucer não temia manter contato com judeus como, por exemplo, Josel von Rosheim. Em abril de 1537, ele não impediu que Wolfgang Capito lhe fizesse uma carta de apresentação para a Saxônia e uma carta de recomendação para Martim Lutero. Pelo contrário, Capito diz expressamente que ele o faz por incumbência de Bucer. ${ }^{115}$ ( $O$ fato de que Lutero se negou a manter um diálogo com Josel é outra questão e não vem ao caso aqui). Além disso, Bucer estava pronto a manter uma discussão aberta com Josel, o que se pode deduzir das observações acima sobre a disputa de Frankfurt em fevereiro de 1539.

${ }^{115}$ Trata-se de uma carta de Wolfgang Capito para Martim Lutero de 26 de abril de 1537 (In: D. Martin Luthers Werke: Kritische Gesamtausgabe. Briefwechsel. Weimar: Böhlau, 1938. v. 8, p. 76-78, n. 3152). 